\title{
Preventing major depression in older medical inpatients: innovation or flight of fancy?
}

Major depression in older medical inpatients is frequent, persistent, and disabling (Cole and Bellavance, 1997). The incidence is $20.5 \%-30.2 \%$ during the 12 months following admission to hospital (Fenton et al., 1997; Cole et al., 2008). Up to $73 \%$ of patients have a protracted course (Koenig et al., 1992; Cole et al., 2006; Koenig, 2006). Moreover, major depression in older medical inpatients appears to be associated with decreased function (Covinsky et al., 1997), increased use of health care services (Koenig et al., 1989; Büla et al., 2001), increased caregiver burden (McCusker et al., 2007), and possibly increased mortality (Cole, 2007).

To date, few healthcare policies or practices address the enormous burden of major depression in older medical inpatients and none does so systematically. Psychiatric consultation may be requested by attending physicians but the majority of older medical inpatients with major depression remain undetected and untreated (Koenig, 2006; Cepoiu et al., 2007). Even if detected and treated, available treatments appear to have limited benefits. Antidepressant treatment is modestly efficacious in older ambulatory patients (McCusker et al., 1998; Williams et al., 2000) but two trials of disease-management models for depression in older medical inpatients have reported high rates of drop-out and non-compliance and limited value in reducing depressive symptoms or improving outcomes (Cole et al., 2002; Oslin et al., 2004). These findings challenge healthcare professionals to find innovative, feasible, effective, inexpensive, and easily implemented approaches to reducing the burden of major depression in this population.

The success of a program to prevent delirium in older medical inpatients (Inouye et al., 1999) offers hope that major depression may be prevented in this population. The delirium program identified older medical inpatients with at least one of six risk factors for delirium and implemented standardized intervention protocols for each of the risk factors present. The program attenuated the risk factors and reduced the incidence of delirium by $40 \%$.

\section{Preventing depression in older subjects}

The Institute of Medicine Report on Preventing Mental Disorders defines three levels of preventive interventions: (1) universal preventive interventions targeted at communities regardless of risk, (2) selective preventive interventions targeted at high-risk groups, and (3) indicated preventive interventions targeted at individuals with early signs or symptoms of mental disorder (Mrazek and Haggerty, 1994). A range of strategies and frameworks for the development and evaluation of interventions to prevent depression have been described - from assessing needs for prevention through identifying target populations to conducting pilot studies, randomized controlled trials, and implementation studies. There seems to be consensus that selective and indicated interventions are probably the levels at which to begin to develop preventive approaches for depression (Cuijpers, 2003; Schoevers et al., 2006; Smit et al., 2006).

A systematic review of 14 trials of selective or indicated interventions to prevent depression in older subjects has reported that such interventions appear to be feasible, although none of these trials was conducted in older medical inpatients (Cole, 2008). Reported trial enrolment rates were $21 \%$ to $100 \%$ (median $45 \%-49 \%$ ), trial completion rates were $53 \%$ to $100 \%$ (median $85 \%$ ), rates of compliance with the interventions were $29 \%$ to $100 \%$ (median $80 \%$ ). Evidence of the effectiveness of these interventions was weak, however, considering the methodological limitations of the trials and the inconsistent results. Only 8 of the 14 trials reported positive results. Among studies that reported risk reductions, absolute risk reductions were $-17 \%$ to $45 \%$ (median $7 \%$ ) and relative risk reductions were $-125 \%$ to $71 \%$ (median $33 \%)$. Nevertheless, some of the interventions were promising, especially those that used educational and cognitive-behavioral techniques, such as the Depression Prevention Course, (Muñoz and Ying, 1993). At the least, the above findings justify efforts to explore the development of programs to prevent major depression in older medical inpatients.

\section{Preventing major depression in older medical inpatients}

Programs to prevent major depression in older medical inpatients require the identification of target patient groups and development of selective or indicated preventive interventions that can be 
implemented on a wide scale. As for identifying target patient groups, two studies have described risk factors for incident major depression in older medical inpatients. The first study reported that depressive symptoms at admission and loss of meaning in life predicted the onset of major depression (Fenton et al., 1997). The second study reported that depressive symptoms at admission, a prior history of depression, and inadequate emotional support predicted the onset of major depression (Cole et al., 2008). Although the attributable fractions for these risk factors have yet to be determined, it is conceivable that older medical inpatients with one or more of these risk factors could be targeted for intervention.

As for development of preventive interventions, the etiology of major depression in older medical inpatients is probably multifactorial. Nonetheless, acute and chronic physical disease and disability likely contribute to a vicious cycle of disempowerment, negative thinking, unpleasant social interactions and feelings of helplessness, and lowered self-esteem and depression (Blazer, 2002; Hinrichsen and Emery, 2005). Interventions that educate, empower, reduce negative thinking, and increase pleasant interactions and feelings of mastery and self-esteem may well contribute to the prevention of major depression in this population.

\section{Including self-management}

Self-management programs for depression use written information, audiotapes, videotapes, and computerized or group courses to assist patients in the management of depressive symptoms (Morgan and Jorm, 2008). In the UK, these interventions are recommended as step 1 in a stepped care program for treating depression in primary care (National Institute for Health and Clinical Excellence, 2007). A meta-analysis suggests that guided (or supported) self-management is more effective than unguided self-management (Gellatly et al., 2007). Although there are no studies of self-management programs to prevent depression, the educational and cognitivebehavioral content of many of the self-management programs are similar to the educational and cognitive-behavioral content of interventions that were feasible and potentially effective in preventing depression in older subjects (Cole, 2008).

\section{Developing a program to prevent major depression in older medical inpatients}

Cognitively intact older medical inpatients at risk of major depression (e.g. those with some depressive symptoms at admission) could receive a guided self-management intervention to prevent major depression. The intervention could involve the patient learning some relatively simple cognitivebehavioral skills to manage depressive thoughts and feelings. Patients could receive a self-management workbook, adapted from an intervention such as the Depression Prevention Course (Muñoz and Ying, 1993) and four 20-30 minute self-management sessions with a trained self-management guide. The workbook and sessions could cover the following topics: information about depression; learning to monitor daily mood level; relaxation exercises; how thoughts, activities, and interpersonal contacts affect mood; and how to identify and change thoughts, activities, and contacts with people that most affect mood level. The self-management guide could use a manual that sets specific goals for each session. The sessions could be conducted face-to-face while the patient was in hospital and, if necessary, by telephone after discharge.

\section{Evaluating a program to prevent major depression in older medical inpatients}

Initial evaluation of such a program would involve determining its feasibility and potential benefits. Can a substantial proportion of older medical inpatients at risk of major depression be screened, identified, and recruited for a feasibility study? Can the intervention be implemented in a timely manner? Will a substantial proportion of enrolled patients comply with and complete the intervention? Is the intervention potentially beneficial in terms of increasing scores on measures of pleasant activities, social contacts, feelings of mastery and self-esteem, and decreasing scores on measures of negative thoughts and depressive symptoms? If the intervention appears to be feasible and potentially beneficial, the next step would involve a randomized controlled trial to determine its effectiveness.

\section{Conclusion}

Preventing major depression in older medical inpatients may be an innovative approach to reducing the frequency of this disorder or a flight of fancy. On the one hand, it is likely that a target population can be identified. There is some evidence that prevention of depression in older subjects is possible. Development of preventive interventions with significant self-management components may increase ease of dissemination and reduce costs. Delivery of the intervention in hospital may increase feasibility because older patients may be more open 
to screening and healthcare interventions in this setting. Finally, a preventive psychosocial intervention may be more acceptable to older medical inpatients, their families, and attending physicians than the use of additional medication. On the other hand, the feasibility of preventive and self-management interventions for depression among older medical inpatients is unknown. Evidence of the effectiveness of preventive and self-management interventions for depression in older subjects is promising but not strong.

Clearly, much research is needed to define target groups and develop and evaluate interventions. If such an approach proves to be feasible and effective, it may provide an opportunity to reduce the burden of major depression in a substantial number of older people.

\section{Conflict of interest}

None.

\section{Martin G. COLE}

Department of Psychiatry, St Mary's Hospital, Montreal, Quebec, and Department of Psychiatry,

McGill University, Montreal, Quebec, Canada

Email: martin.cole@ssss.gouv.qc.ca

\section{References}

Blazer, D. G. (2002). Self-efficacy and depression in late life: a primary prevention proposal. Aging Mental Health, 6, 315-324.

Büla, C. J., Wietlisbach, V., Burnand, B. and Yersin, B. (2001). Depressive symptoms as a predictor of 6-month outcomes and services utilization in elderly medical inpatients. Archives of Internal Medicine, 161, 2609-2615.

Cepoiu, M., McCusker, J., Cole, M. G., Sewitch, M. and Ciampi, A. (2007). Recognition of depression in older medical inpatients. Fournal of General Internal Medicine, 22, 559-564.

Cole, M. G. (2007). Does depression in older medical inpatients predict mortality? A systematic review. General Hospital Psychiatry, 29, 425-430.

Cole, M. G. (2008). Brief interventions to prevent depression in older subjects: a systematic review of feasibility and effectiveness. American fournal of Geriatric Psychiatry, 16, 435-443.

Cole, M. G. and Bellavance, F. (1997). Depression in elderly medical inpatients: a meta-analysis of outcomes. Canadian Medical Association fournal, 157, 1055-1060.

Cole, M. G. et al. (2002). Systematic detection and multidisciplinary care of depression in older medical patients: a randomized trial. Canadian Medical Association fournal, 167, 753-759.

Cole, M. G., McCusker, J., Ciampi, A., Windholz, S., Latimer, E. and Belzile, E. (2006). The prognosis of major and minor depression in older medical inpatients. American fournal of Geriatric Psychiatry, 14, 966-975.
Cole, M. G., McCusker, J., Ciampi, A. and Belzile, E. (2008). Risk factors for major depression in older medical inpatients: a prospective study. American fournal of Geriatric Psychiatry, 16, 175-178.

Covinsky, K. E., Fortinsky, R. H., Palmer, R. M., Kresevic, D. M. and Landefeld, C. S. (1997). Relation between symptoms of depression and health status outcomes in acutely ill hospitalized older persons. Annals of Internal Medicine, 126, 417-425.

Cuijpers, P. (2003). Examining the effects of prevention programs on the incidence of new cases of mental disorders: the lack of statistical power. American fournal of Psychiatry, 160, 1385-1391.

Fenton, F. R., Cole, M. G., Engelsmann, F. and Mansouri, I. (1997). Depression in older medical inpatients: one-year course and outcome. International fournal of Geriatric Psychiatry, 12, 389-394.

Gellatly, J., Bower, P., Hennessy, S., Richards, D., Gilbody, S. and Lovell, K. (2007). What makes self-help interventions effective in the management of depressive symptoms? Meta-analysis and meta-regression. Psychological Medicine, 37, 1217-1228.

Hinrichsen, G. A. and Emery, E. E. (2005). Interpersonal factors and late-life depression. Clinical Psychology: Science and Practice, 12, 264-275.

Inouye, S. K. et al. (1999). A multicomponent intervention to prevent delirium in hospitalized older patients. New England fournal of Medicine, 340, 669-720.

Koenig, H. G. (2006). Depression outcome in inpatients with congestive heart failure. Archives of Internal Medicine, 166, 991-996.

Koenig, H. G., Shelp, F., Goli, V., Cohen, H. J. and Blazer, D. G. (1989). Survival and health care utilization in elderly medical inpatients with major depression. fournal of the American Geriatrics Society, 37, 599-606.

Koenig, H. G., Goli, V., Shelp, F., Kudler, H. S., Cohen, H. J. and Blazer, D. G. (1992). Major depression in hospitalized medically-ill older men: documentation, management, and outcome. International fournal of Geriatric Psychiatry, 7, 25-34.

McCusker, J., Cole, M., Keller, E., Bellavance, F. and Berard, A. (1998). Effectiveness of treatments of depression in older ambulatory patients. Archives of Internal Medicine, 158, 705-712.

McCusker, J., Latimer, E., Cole, M. G., Ciampi, A. and Sewitch, M. (2007). Major depression among medically ill elders contributes to sustained poor mental health in their informal caregivers. Age and Ageing, 36, 400-406.

Morgan, A. J. and Jorm, A. F. (2008). Self-help interventions for depressive disorders and depressive symptoms: a systematic review. Annals of General Psychiatry, 7, 13. doi: 10.1186/1744-859X-7-13.

Mrazek, P. J. and Haggerty, R. J. (eds.) (1994). Reducing Risks for Mental Disorders: Frontiers for Preventive Intervention Research. Washington, DC: National Academy Press.

Muñoz, R. F. and Ying, Y. (eds.) (1993). The Prevention of Depression: Research and Practice. Baltimore, MD: John Hopkins University Press.

National Institute for Health and Clinical Excellence (2007). Quick Reference Guide (Amended) - Depression: 
Management of Depression in Primary and Secondary Care. London, U.K.: National Institute for Health and Clinical Excellence.

Oslin, D. W. et al. (2004). Treatment effects from upbeat: a randomized trial of care management for behavioral health problems in hospitalized elderly patients. Fournal of Geriatric Psychiatry and Neurology, 17, 99-106.

Schoevers, R. A. et al. (2006). Prevention of late-life depression in primary care: do we know where to begin? American fournal of Psychiatry, 163, 1611-1621.
Smit, F., Ederveen, A., Cuijpers, P., Deeg, D. and

Beekman, A. (2006). Opportunities for costeffective prevention of late-life depression: an epidemiological approach. Archives of General Psychiatry, 63, 290-296.

Williams, J. W., Mulrow, C. D., Chiquette, E., Hitchcock-Noë1, P., Aguilar, C. and Cornell, J.

(2000). A systematic review of newer pharmacotherapies for depression in adults: evidence report summary. Annals of Internal Medicine, 132, 743-756. 